\title{
A technique for demonstrating the inhibitory function of $\mathbf{S}^{\Delta}$
}

JAMES M. CORNELL AND HARRY STRUB

UNIVERSITY OF WATERLOO

\begin{abstract}
Abstraet
Rats were trained either 52 or $92 \mathrm{hr}$. in an operant discrimination involving two $\mathrm{S}^{\mathrm{D}} \mathrm{S}$ and one $\mathrm{S}^{\Delta}$. During extinction, comparisons of the number of responses to individual and to combined stimuli indicated that: (1) $\mathrm{S}^{\Delta}$ exerts an inhibitory effect when combined with one or both $\mathrm{S}^{\mathrm{D}_{\mathrm{S}}}$; (2) excitatory control summates; and (3) an amount-of-training effect may have been present. Problem
\end{abstract}

The procedure for establishing an operant discrimination is straight-forward. The $\mathrm{S}$ is reinforced for responding in the presence of some stimulus event $\left(\mathrm{S}^{\mathrm{D}}\right)$ and extinguished in the presence of some different stimulus event $\left(S^{\Delta}\right)$. A discrimination is said to be established when the $S$ responds differentially as a function of the presence of $\mathrm{S}^{D}$ or $\mathrm{S}^{\Delta}$. Extending the terminology of Pavlov (1927) to the operant procedure it may be said that the $S^{D}$ functions as an excitatory stimulus while the $\mathrm{S}^{\Delta}$ functions as an inhibitory stimulus. Used in this manner the terms excitatory and inhibitory are descriptive and need not imply anything regarding the physiology of behavior.

In a recent paper, Jenkins (1965) discusses some of the logical problems involved in assigning inhibitory control to a stimulus in the sense that it "...is acting as a signal for not responding." He states (p. 56), that "the problem is how to distinguish the presence of an inhibitory effect from the absence or reduction of an excitatory effect." He proposes the use of generalization tests as a technique for resolving the problem. The present paper proposes to extend Pavlov's (1927, pp. 68ff.) original procedure for demonstrating inhibitory stimulus control to the operant situation as an alternative to the generalization test technique

Specifically, two $\mathrm{S}^{\mathrm{D}} \mathrm{S}$ and one $\mathrm{S}^{\Delta}$ were separately conditioned and the three stimuli $\left(\mathrm{S}^{D_{1}}, \mathrm{~S}^{\mathrm{D}_{2}}\right.$, and $\left.\mathrm{S}^{\Delta}\right)$ were then presented both individually and in the four

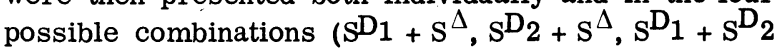
$+\mathrm{S}^{\Delta}$, and $\mathrm{SD}_{1}+\mathrm{S}_{2}$ ) during extinction. Pavlov's logic is our logic-if the $S^{\Delta}$ does exert inhibitory control then a decrement in responding should be observed whenever $\mathrm{S} \Delta$ is paired with either one or two $\mathrm{SD}_{\mathrm{S}}$ during extinction. Method

Subjects. The Ss were six male albino rats 120 days old at the start of discrimination training. They were maintained at approximately $85 \%$ of their ad lib weight with corrections for growth made as necessary. Three Ss received 92 and three received $52 \mathrm{hr}$. of discrimination training. Initially, the 52-hr. Ss were intended as a replication of the results obtained with the 92-hr. Ss.
Apparatus. The apparatus employed in the experiment was a two-lever Skinner-Box (Grason-Stadler Model 3125B). Three $7.5 \mathrm{w} .110 \mathrm{VAC}$ pilot lights with 1-in diameter white lenses were located on the same wall as the levers and the food cup. A light was located about 2-in above each lever while the third light was centered between them and above the food cup. The end lights were the $\mathrm{SD}_{\mathrm{S}}$ and the center light was $\mathrm{S}^{\Delta}$.

Discrimination Training: 92-hr. Ss. The Ss were trained to press the left lever. Following pretraining the Ss were given four 2-hr. sessions where lever pressing was reinforced on a VI $30 \mathrm{sec}$. schedule in the presence of either $\mathrm{S}_{1}$ or $\mathrm{S}_{2}$ while responding during $\mathrm{S}^{\Delta}$ was extinguished. Each separate stimulus was presented for $5 \mathrm{~min}$. at a time. $\mathrm{S}^{\Delta}$ was on for a total amount of time equal to half the total session time. The order of presentation of the three stimuli was varied. The only illumination in the S's compartment was that provided by the stimulus lights. Reinforcers were $\mathbf{0 4 5}$ $\mathrm{gm}$ food pellets. Beginning session five the reinforcement schedule was changed to VI $1 \mathrm{~min}$. and the sessions lengthened to $4 \mathrm{hr}$. During the last five sessions the duration of the stimulus presentations was made variable between 1 and $5 \mathrm{~min}$. with an average duration of $3 \mathrm{~min}$. The Ss received a total of $214-\mathrm{hr}$. sessions.

Discrimination Training: 52-hr. Ss. The 52$\mathrm{hr}$. Ss received training identical to the $92-\mathrm{hr}$. Ss with the following exceptions: (1) they were trained to press the right lever, (2) the duration of the separate stimulus presentations was variable (average $=3 \mathrm{~min}$.) throughout training, and (3) they received only 11 4-hr. discrimination training sessions following the four initial 2-hr. sessions.

Extinction Testing. All Ss were tested on the two days following the last training session. The extinction test consisted of $201-\mathrm{min}$. presentations of each of the three separate stimuli and each of the four combinations of the training stimuli on the first day and 10 additional 1-min. presentations of the seven test conditions on the second day. The order of presentation was $s_{1}^{D_{1}}, s^{\Delta}, s_{2}^{D_{2}}, s^{D_{1}}+s^{\Delta}, s_{1}^{D_{1}}+s_{2}^{D_{2}}$,

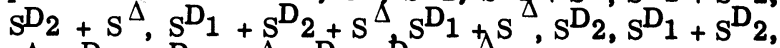

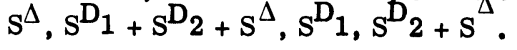

Results and Diseussion

The discrimination ratios $\left(\mathrm{S}^{\Delta} / \mathrm{S}^{\mathrm{D}}\right)$ for both the 52and $92-\mathrm{hr}$. Ss were less than .10 prior to the test, although the 92-hr. Ss took somewhat longer to reach the $10 \%$ level than the 52-hr. Ss. The most likely reason for this is that, when $S^{\Delta}$ periods are of a fixed duration and the training is prolonged, there is a tendency for 


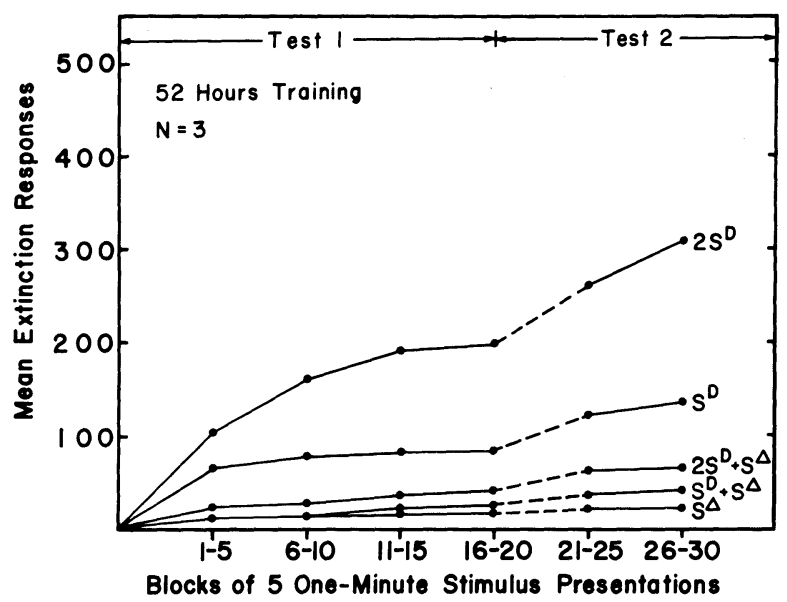

Fig. 1. Mean cumulative extinction responses made by $52-\mathrm{hr}$. Ss in presence of separate and combined excitatory $\left(S^{D}\right)$ and inhibitory $\left(\mathbf{S}^{\Delta}\right)$ stimuli.

Ss to make temporal discrimination similar to those observed in FI schedules where anticipatory responding occurs toward the end of the interval. Because of this difference the hours of training may not adequately reflect the relative development of the discrimination for the two groups of Ss.

The extinction responses made in the presence of the seven stimulus conditions for the 52- and 92-hr. Ss are presented in Figs. 1 and 2, respectively. The extinction responding in the presence of the two individual $\mathrm{S}^{\mathrm{D}} \mathrm{S}$ has been averaged and the resulting curve is labelled $S^{D}$ in the figures. Similarly, the extinction responding in the presence of the combined $S^{D_{1}}+S^{\Delta}$ and $S^{D}+S^{\Delta}$ conditions have been averaged and plotted as $\mathrm{S}^{\mathrm{D}}+\mathrm{S}^{\Delta}$.

On the basis of the data it is clear that the simultaneous presentation of both excitatory and inhibitory stimuli during extinction does provide evidence for the conclusion that the latter functions as a signal for not responding (i.e., it exerts inhibitory control) since, whenever $S \Delta$ was presented in combination with one or two $\mathrm{S}^{\mathrm{D}} \mathrm{s}$, there was a decrement in responding. This was true of every animal tested when his responding in the presence of the excitatory plus inhibitory combination was compared with his responding in the presence of the excitatory component alone. Although not of paramount interest in this report, it should be noted that our results have replicated Wolf's (1963) results for the

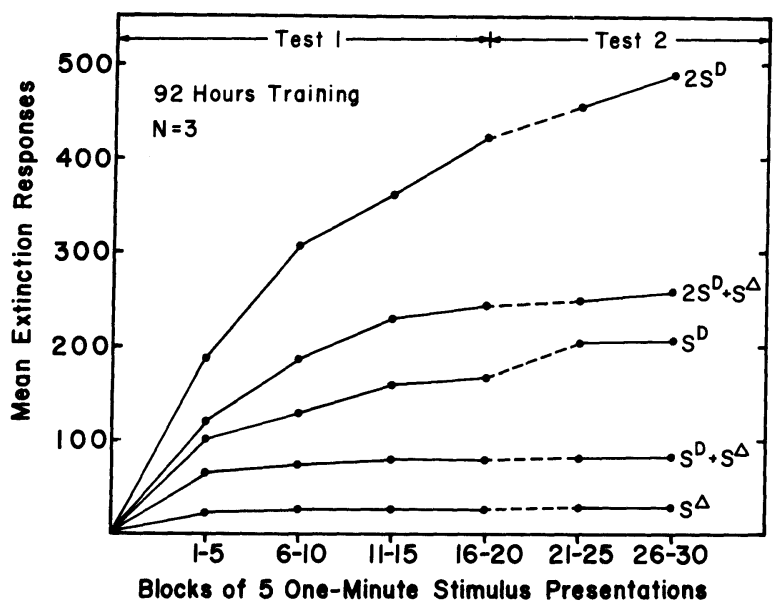

Fig. 2. Mean cumulative extinction responses made by $92-\mathrm{hr}$. Ss in presence of separate and combined excitatory $\left(S^{D}\right)$ and inhibitory $\left(\mathbf{S}^{\Delta}\right)$ stimuli.

summation of combined $\mathrm{S}^{\mathrm{D}} \mathrm{S}$.

An unexpected product of the research was the difference observed between the test performance of the 52- and 92-hr. Ss. While the responding in the presence of $\mathrm{S}^{\Delta}$ alone remained stable there were differences in the overall amount of extinction responding and in the relative positions of the test stimulus conditions. The most likely reason for the difference in overall responding is that the Ss received different amounts of training.

Most interesting is the fact that the number of responses made to the combined excitatory and inhibitory stimuli increased from 52 to $92 \mathrm{hr}$. of training (see Figs. 1 and 2). Although the difference is not significant $(p>10<20)$ the trend suggests that the development of inhibitory control may not parallel the development of excitatory control. Research is currently underway to determine the interaction between amountof-training and the development of excitatory and inhibitory stimulus control.

\section{References}

Jenkins, H. M. Generalization gradients and the concept of inhibition. In D. J. Mostofsky (Ed.), Stimulus generalization. Stanford: Stanford University Press, 1965. Pp. 55-61.

Pavlov, I. P. Conditioned reflexes. (Trans. by G. V. Anrep) London: Oxford University Press, 1927.

Wolf, M. M. Some effects of combined $\mathrm{S}^{\mathrm{D}} \mathrm{s}$. J. exp. Anal. Behav., $1963,6,343-347$. 